\title{
Student-led development and evaluation of a community pharmacy-based cardiovascular risk assessment
}

\author{
Christine Filion-Murphy, Lyndsey Hands, Lyndsey Hockham, Laura Kirkpatrick, \\ Sinead McNamara, Alison Strath, lain Rowe, Helen Vosper \\ Robert Gordon University
}

\section{Introduction}

\section{The pharmacy education context}

Higher Education enhancement agendas are generally united in their aim to improve employability by supporting the development of curricula that promote acquisition of professional skills. The challenge for those involved in teaching is thus the provision of aligned curricula with opportunities for engagement with 'real-life' learning activities that are relevant to the workplace. Furthermore, there must be opportunities for students to be assessed in such 'professional competencies'. This could be seen as a paradigm shift for undergraduate Pharmacy programmes, the delivery of which is now overseen by the General Pharmaceutical Council (GPhC). The most recent Standards for the Initial Education and Training for Pharmacists (2010) make it clear that such programmes will no longer produce scientists who may go on to become healthcare professionals; rather, they will now produce healthcare professionals whose practice is underpinned by a strong grounding in relevant pharmaceutical science. In medicine and other healthcare courses, the development of professional competencies is generally provided within the clinical placement component of the course. A combination of both a lack of funding and lack of opportunity for placement has become a challenge for pharmacy courses. Existing placement experiences tend to occur towards the end of the programme, and this 'late and limited' exposure to practice is recognised as being one factor with impact on the ability of new graduates to apply their knowledge and skills in workplace contexts (Smith and Darracott, 2011). Additionally, the lack of clinical experience makes it difficult for students in the earlier years of their course to contextualise their theoretical learning (especially the underpinning science), leading to an artificial segregation of the science and practice sections of the course. Lack of exposure to professional experiences within an undergraduate curriculum can also affect how the students develop professional identity and this concept of 'professionalism' and the way in which it is developed throughout the course is another critical element of undergraduate education. Beyond these pedagogical aspirations, a number of more pragmatic drivers for change have particular significance in the Scottish context.

\section{The Scottish context}

The current UK model for most undergraduate pharmacy programmes is the so-called ' $4+1$ ' structure: after completion of a four-year degree course, successful students take up a oneyear pre-registration place, where they will receive the bulk of their professional experience (Smith and Darracott, 2011). Success in the pre-registration examination permits entry to the professional register. Concerns about this fragmentation and the lack of clinical exposure throughout the undergraduate years have led to a move in England towards a five-year integrated programme, which is a particular problem for Scotland, where there are simply not enough traditional placement opportunities for the numbers of students currently enrolled on 
courses at the two Scottish Schools of Pharmacy - those unable to access Scottish pre-reg. posts have until now been able to find them in England, but once the integrated programme south of the border is established, these opportunities may disappear.

Furthermore, future pharmacists are seen as playing a central role in the delivery of the 'pharmaceutical care' model described within the Scottish Government's '2020 Vision' for healthcare (NHS Scotland, 2011). Pharmaceutical care is described as "a philosophy ... for the responsible provision of drug therapy for the purpose of achieving definite outcomes that improve a patient's quality of life." In order to achieve this vision, it is expected that, by 2023, all pharmacists providing clinical care will be NHS-accredited clinical pharmacist independent prescribers. In this changing political and medical context, there is a clear need for the pharmacist's developing role to be recognised as part of a multi-disciplinary team. The relationship between doctors and pharmacists is seen as critical and ripe for improvement.

It is possible that future political decisions may open up the clinical environment to pharmacy students, but there are no guarantees of this. If Higher Education Institutions are to produce graduates ready to meet the challenges of this new future, they must be more creative in their approach to the concept of 'professional experiences.' Simulation is one such approach and has the advantage that staff can add activities that support exploration of the links between science and practice (Vosper et al, 2013). Such activities also lend themselves well to assessment, as this level of control can ensure a reasonably equitable experience for all students.

\section{Students as partners}

That there is a need for curriculum review, as outlined above, also means that there is associated opportunity for innovation. As one of RGU's aspirations is to 'empower students to shape their learning experience and that of their peers', involving students in curriculum design is a way of fulfilling this. This paper describes an initiative in which a group of undergraduate MPharm students developed, implemented and evaluated an existing teaching and learning activity (involving a community pharmacy-based cardiovascular risk assessment) to support the achievement of 'professional' outcomes. Management of cardiovascular risk by the pharmacist, in partnership with the GP or secondary care, is one of the tasks that falls well within the '2020 Vision'.

\section{The RGU Pharmacy student partnership}

The partnership described within this paper grew out of a Higher Education Academy Change Initiative which explored the strategic embedding of simulation within a pharmacy undergraduate curriculum as a pedagogically-robust adjunct to work-based placement. This involved working with stakeholders to produce a 'compendium of effective simulation practice' to support educators in planning curricula. Students were recognised as key stakeholders, but it soon became clear that they were 'unequal partners' because they lacked training in educational theory and practice. Summer studentships (funded by NHS Education Scotland) were based on the RGU in-house PgCert provision and focused upon specific enhancement initiatives (including the simulation project). This proved so promising (in terms of outputs/outcomes) that it was decided to form a student-led learning enhancement team, to be piloted in the session 2013-14. The summer studentships were 


\section{Articles}

used as the vehicle to recruit students to the learning enhancement team - the initial team was made up of the staff and students involved in the first studentships and numbers were built during the second wave of summer studentships in 2014. The team is well-placed to influence curriculum development, as members of staff leading the initiative have direct responsibility for teaching and learning development. In terms of impact, students are able to select enhancement projects which address areas that they believe to be key. Staff simply facilitate this activity. Achievements of this team include:

- completion of a number of enhancement initiatives that have directly influenced the curriculum (including the cardiovascular risk assessment development described here).

- a number of publications in peer-reviewed journals, as well as conference presentations (including, at the HEA national conference in July 2014, a one-hour discussion session which specifically explored the risks and benefits of student partnerships).

- establishment of a student-led Patient Safety Chapter of the Institute for Healthcare Improvement. This group has established a full programme of learning activities and events used or accessed by approximately 200 undergraduate students and has significantly contributed to the patient safety aspects of the curriculum.

- The team has provided peer-teaching and support to other students, one example being the project described within this paper - part of the work was carried out by final-year project students (L Ho, LK, SMcN), supported by members of the student learning enhancement team (CF-M, L Ha).

Despite all these benefits, working with students in this way is not without its risks. Students' challenging the curriculum can be problematic for some staff and students need resilience to deal with this. Furthermore, there is a significant time input required, which has the potential for negative impact upon academic performance. Some anecdotal evidence also suggested that student relationships were affected, as some peers felt that the team enjoyed special privilege. To deal with this, the team has worked with the HEA on the Students as Partners in the Curriculum Change Programme. The outcomes of this process have involved seeking ways to improve the articulation of the enhancement team with existing mechanisms such as course management teams and staff-student liaison committees. The students decided that the biggest challenge facing them as 'partners in the curriculum' was the issue of balancing power with responsibility; consequently, they decided that it would be better for students to have a degree of control in small areas of the curriculum. The suggested partnership model is therefore negotiation between staff and students to identify areas of priority development, followed by action-research projects to improve the quality of the curriculum in these discrete areas. The rest of the paper illustrates this approach by describing one such project and reflecting on its impact. All of the work was carried out by the students - staff (AS, IR, HV) merely acted in a mentoring capacity.

\section{Methodology}

The cardiovascular risk assessment, already used as a teaching and learning activity in the module Clinical Pharmacology and Therapeutics-1, was just a single activity, with a brief introduction to the main technical skills involved. Student feedback was traditionally very positive, with students believing that it prepared them well for the examination. However, 
they often expressed concerns that they found it stressful because they felt they lacked the full range of skills to deliver an effective risk assessment. Staff and students felt there were opportunities to deliver an enhanced version which also offered opportunities for integration of practice and science.

\section{Ethics and governance}

The ethical issues surrounding this work were considered in association with the School of Pharmacy and Life Sciences governance procedures.

\section{Project phases}

This action research project used a mixed-method approach. There were two initial data collection phases and the results of these were analysed to yield information that was then used to support the third phase: the development, implementation and evaluation of a teaching, learning and assessment tool.

Phase 1 involved revisiting the existing cardiovascular risk assessment, with a focus-group approach to explore the experiences of participants in a group context (group dynamics are an important element of teaching and learning activities). The structure for these sessions comprised questions concerning the strengths and weaknesses of the existing risk assessment, consideration of the drivers affecting the educational provision, ways in which it might be improved and identification of relevant stakeholders whose opinions should be sought in Phase 2. Those invited to participate in this phase included teaching staff involved in this module and members of the school Student Learning Enhancement. All sessions were recorded and transcribed verbatim.

Phase 2 comprised a series of structured interviews with individuals identified as key stakeholders in the development of an appropriate cardiovascular risk assessment-based teaching and learning tool. Participants included staff members involved in teaching, who had not participated in the original focus group, and two pharmacists, one of them with experience of running the risk assessment in a busy Glasgow pharmacy. A GP and a dietitian were also invited to participate. Interviews were based on a template developed by researchers during Phase 1.

A 'realist' thematic analysis approach was selected and, in determining the themes, attention was paid not only to frequency, but also to whether or not the data captured issues of importance to the research questions. The themes were independently identified by three student researchers (LH, LK and SM) and confirmed by the supervisor (HV). No discrepancies were identified. The results of the thematic analysis were used to formulate Phase 3: a teaching plan for Semester 2 activities. Evaluation of the implementation was carried out using thematic analysis of data from the University's Student Experience Questionnaire (one of the strands of the University's mechanism for collecting, reviewing and responding to student feedback). This data was supported and enriched by a modulespecific online questionnaire that was made available, via email invitation, to all second-year MPharm students. This contained a mixture of 'likert-scale' responses, as well as opportunities for open-text responses, and the identities of the respondents were not known to the research team. A single reminder was posted via social media and the results were again considered by thematic analysis (CF-M and HV). 


\section{Results and discussion}

\section{Phases 1 and 2: Student-led development of an enhanced risk assessment}

A full analysis of the data obtained in this project is beyond the scope of this paper, so the authors have chosen to present a selection of themes: these, the most commonly recurring themes, were also selected because of their saliency with respect to drivers for change for pharmacy education.

\section{Relationship between pharmacist and general practitioner}

"You have to be careful... sometimes you'll refer a patient [and]... get a snooty letter back from the GP saying 'What are you doing - this blood pressure is actually normal for [this patient]!'”

The reforms described in the Scottish Government's 2020 Vision for health and social care are driven at least partly by a recognition that the pharmacist is currently under-utilised. Effective change will require the building of new relationships between some healthcare professionals and the strengthening of existing ones. The relationship between pharmacist and GP is recognised as being one of the most critical in terms of delivering on this new 'pharmaceutical care' model. Interestingly, there is relatively little information in the literature exploring this relationship. The few studies that are available indicate that this may in fact be one of the barriers to change: there seems to be little enthusiasm by General Practitioners for any expansion in the clinical services offered by pharmacists. A study by Bryant et al (2009) gives some insight into what might be responsible for this inertia. The results of this study indicated that GPs were very happy with what they perceive to be the 'medicines management' role of the pharmacist, but did not support the involvement of pharmacists in screening for chronic conditions or selecting suitable medication for a patient, possibly reflecting concerns that pharmacist involvement in clinical care is driven by desire to increase footfall; indeed, the study by Bryant suggests that one of the main issues underpinning GP reservations is their concern about commercial pressures that may influence pharmacists' clinical decision-making - whilst almost all the pharmacists polled believed that they could give unbiased advice on the use of medicines, only around $40 \%$ of GPs agreed.

One of the arguments in favour of broadening the pharmacist's role is that it can reduce time burdens for GPs. This view was not shared by the participants in the Bryant study and, indeed, was echoed in the results of this study: there was a concern that much of the work done within pharmacies is simply duplication and increases GP workload (Horgan et al, 2010). However, many of the problems concerning pharmacist-GP relationships could be resolved if such services were to be developed in collaboration, with the articulation of clear referral pathways and effective sharing of information. In Scotland, the introduction of the Chronic Medication Service (a system which permits patients with long-term conditions to register with a community pharmacy, entering into a shared-care arrangement with their pharmacist and GP) offers increased opportunity for such collaboration:

"We're getting better now [in terms of our working relationship] with the C[hronic] M[edication] S[ervice]..." 
Interestingly, the barriers are not one-sided: pharmacists themselves also expressed reluctance to take on a more clinical role, owing largely to concerns about a lack of clinical knowledge, but also about environmental factors, such as lack of appropriate space, privacy etc. (Bryant et al, 2009). This is interesting in the light of growing awareness of the relevance of human factors in health care: task performance is a product of the environment, and that includes the physical space itself, the equipment and the people within that space.

Understanding of this environment is key to optimising performance and this is something which has relevance for all healthcare professionals, as recognised in the Human Factors in Healthcare Concordat (National Quality Board, 2013).

Recommendation 1: It should be clear that the pharmacy-based risk assessment is actually risk estimation.

Recommendation 2: Learning and teaching activities based upon risk assessment should include a multi-disciplinary perspective and consider how information may best be shared with other healthcare professionals.

Recommendation 3: Learning and teaching activities should include exposure to the Chronic Medication Service.

\section{Recommendation 4: Education about human factors should form part of clinical training.}

\section{Recommendation 5: Opportunities for shared learning experiences with medical students should be explored.}

Addressing the mismatch between 'ideal' and 'real' clinical environments: the value of simulation

The existing teaching in this module involves student participation in a simulated risk assessment. The focus groups in Phase 1 considered the strengths and weaknesses of using simulation to support the development of clinical competencies. Although simulation is not new to UK pharmacy courses, there is little consistency in its use, and there is very little evidence in the literature to support its value in terms of delivering course outcomes. There is a greater body of evidence for US pharmacy simulation (Seybert, 2011), but most of that which is described involves the sort of high risk/rare scenarios involved in medical education, but with the inclusion of a pharmacist on the healthcare team. The cardiovascular risk assessment is different, in that it involves routine ('everyday') tasks. In the initial focus group discussions, one student with ten years' work experience in a community pharmacy suggested that one of the problems with the existing simulated risk assessment was that while the clinical scenario was realistic - the environmental aspects were less so.

Reflections on this aspect of the work have been published as part of another study (Regan et al, 2014), but essentially it was suggested that unrealistic environments deprive the student of the opportunity to experience the reality of practice, meaning $s /$ he is not well prepared for the workplace.

A key educational issue arising from the Francis Report into the failings at Mid-Staffordshire Hospital was the notion of equipping students with the skills and resilience that would allow them to stand up to poor practice behaviours. However, part of this involves students' and new practitioners' ability to recognise when the environment has deviated so far from the 
ideal that patient safety is compromised. Furthermore, lack of exposure to anything other than 'gold standard' environments can impact on job satisfaction and morale.

\section{Recommendation 6: Teaching and learning activities should explore the mismatch between 'ideal' and 'real' environments.}

\section{Recommendation 7: Teaching and learning activities should explore both positive and negative behaviours with respect to the cardiovascular risk assessment.}

\section{Giving advice about lifestyle modification}

"[We are taught lots around actual treatments but] there's less training, I have to say, in the lifestyle advice and motivational interviewing type stuff."

\section{GP}

"A lot of what [dietitians] do is around behavioural change, so... in other words, negotiating with the patient and working with them."

Dietitian

At the moment, there are limited opportunities for community pharmacists to make prescribing decisions, so the largest part of the strategy to reduce risk will involve lifestyle modifications. This will include attempting to support patients in healthy eating and weight management. This is not as straightforward as it might sound: there is an acknowledged lack of training to support weight and diet management in primary care, so much so that there are professional groups who believe it should not be managed in this way (McClinchy et al, 2013). There are some contributory factors to this situation, not least that practitioners (despite their education concerning environmental and genetic factors) can display a judgmental attitude which suggests that they believe the patient's behaviour to be the primary cause of obesity and related problems. It is also true that eating and activity behaviours are complex, often with strong a psychological component. Management can also be acutely affected by the patient's lifestyle - working patterns, childcare, physical limitations and support networks being only a selection of the pressures that may exist. Consequently, as the GP interviewed in this study observed, it is critical to make advice specific to each patient. Another issue is that many initiatives aimed at improving health tend to consider weight management rather than healthy eating. This focus is a response to the clear link between obesity and cardiovascular risk. However, while a reduction in weight will reduce risk, this benefit will be sustained only if the patient adopts a healthy diet. Many weight management interventions deal with short-term weight loss and do not address barriers to healthy eating.

Recommendation 8: Teaching and learning activities should include exploration of what constitutes a cardioprotective diet and how this may be explained to the patient.

Recommendation 9: Strategies for assessing patient understanding should be built in to the simulated cardiovascular risk assessment. 
Non technical skills

"And I think quite a lot of it comes down to communication skills... if you don't have a motivational interviewing skill [then it won't work]"

GP

Part of the '2020 Vision' for healthcare enshrines the concept of patients as 'co-producers' of the health outcomes in terms of the management of their own condition. 'Co-production' is defined as "active dialogue and engagement between people who use services and those that provide them, putting the service user on the same level as the service provider." Achieving this level of interaction will require the pharmacist to have a number of the socalled 'soft skills' such as communication, conflict resolution and adaptability. Some US studies have shown that pharmacy simulation-based teaching and learning activities are effective at developing such non-technical skills, as well as improving critical thinking skills. There is some (albeit limited) evidence to suggest that this may improve clinical performance. However, for this to be effective, it is important that assessment of soft skills is not tacit. Learning outcomes need to be clearly articulated and effective feedback must be given. This feedback should be couched in terms of the learning outcomes and should be diagnostic, in that it allows students to understand for themselves the difference between their performance and that articulated in the learning outcomes. Strategies for addressing the gap need to be considered - thus effective briefing and debriefing should be part of the process (Fanning and Gaba, 2007).

\section{Recommendation 10: Non-technical skills training with opportunity for effective debriefing should form part of the risk assessment simulation.}

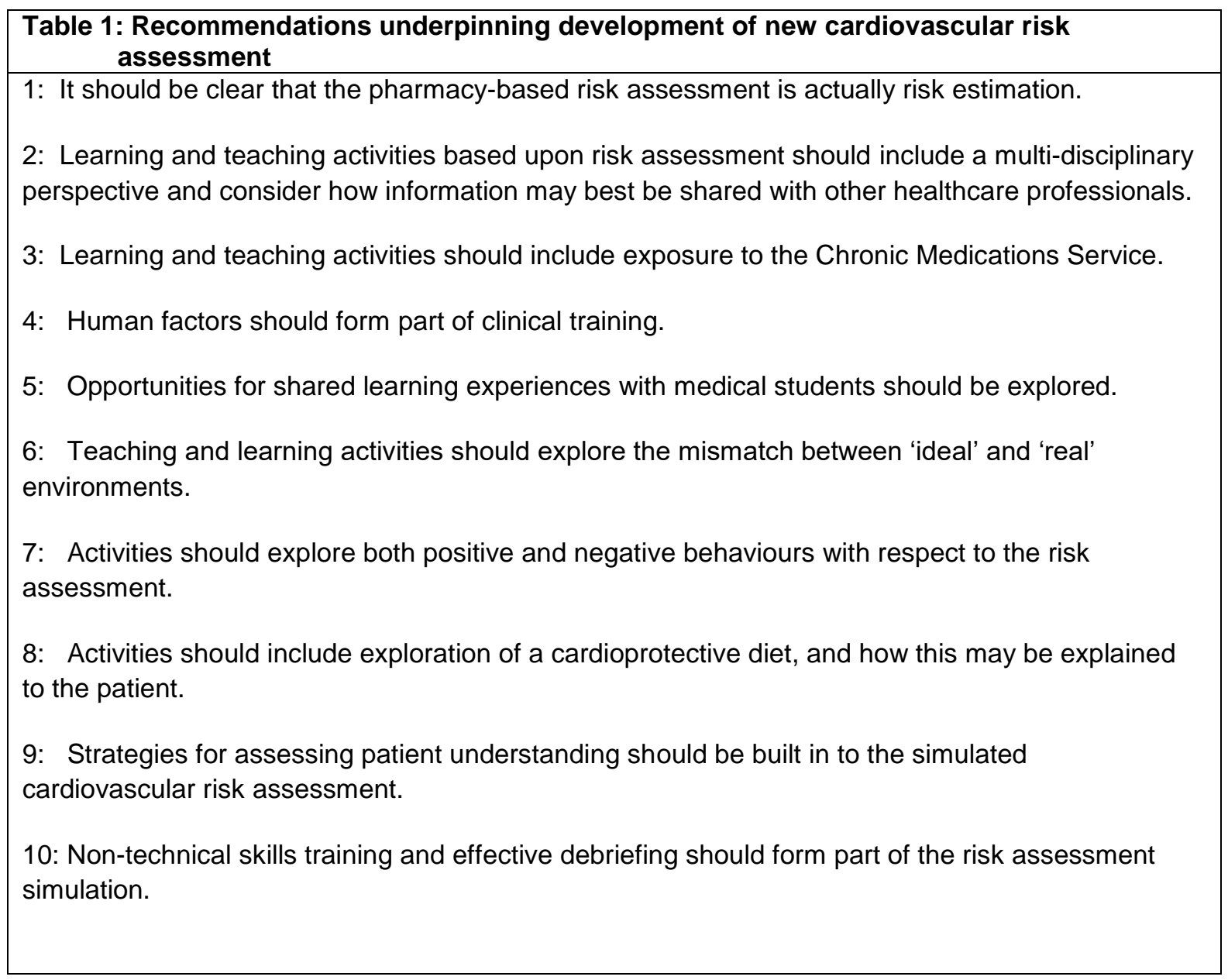




\section{Developing the new risk assessment}

If all the recommendations were to be accommodated, it was clear that much more time would need to be given over to the risk assessment. This was considered to be appropriate - most of the second-semester courseworks were already devoted to the cardiovascular system and the lectures dealt with the science underpinning the factors that contribute to risk. Seven coursework sessions were available within the module, although it was noticed that many of the new elements could be considered as 'professional skills'. It was decided that this would offer an opportunity to develop teaching sessions integrated with a secondyear professional module, which would also support the students in integrating their science and practice knowledge. An outline teaching plan was developed as outlined in Table 2.

\section{Table 2: Outline plan for Semester 2}

\begin{tabular}{l}
\hline Activities \\
\hline Week 1. Introduction to the risk assessment covering: \\
value and limitations; patient history; near-patient testing; risk algorithms; practical skills; non- \\
technical skills; checking patient understanding; referral pathways; \\
GP-pharmacist relationship. \\
\hline Week 2. Development of non-technical skills covering: \\
human factors; concepts of 'good', 'acceptable' and 'poor' professional behaviours. Students to film \\
a short consultation - clips to support online forum activities that will underpin the development of a \\
rubric to support achievement in the risk assessment itself. \\
\hline Week 3. Failing in safety. \\
In this week, they have the opportunity to run a full risk assessment on a member of teaching staff. \\
Teaching staff will also explore student understanding of the science underpinning the 'clinical \\
decisions' students are making. Effective debriefing will help the students to refine their \\
understanding (as well as improve their rubric). \\
\hline Week 4. Finalising the rubric and planning approach for Week 5. \\
\hline Week 5. Risk assessment for real! \\
\hline Week 6. Opportunity for reflection; preparation for summative assessment which will involve \\
watching videos produced by the students and answering questions concerning the risk \\
assessment and also exploring the underpinning science. \\
\hline After a three-week gap for consolidation, the students will take their summative assessment. \\
\hline
\end{tabular}

\section{Phase 3: Implementation and evaluation}

Staff delivered the student-developed teaching plan as it stood. Engagement with the activities was incredibly high - attendance for the coursework sessions and participation in the online forum was 99\%). Anecdotally, staff reported students as actively engaged (and happy!) throughout the sessions. The response rate for the module-specific questionnaire was only $12 \%$, with the timing most likely to be the main factor - most students were on vacation at this point. However, the response rate for the Student Experience Questionnaire was much higher (52\%). The SEQ contains sections for each module, so there was a significant amount of qualitative data available for this module.

Anecdotal evidence suggested that students found the courseworks challenging but useful in supporting their progress through the module. Staff felt that student input was very powerful: essentially, weeks $2-6$ of the activities involved students in collaborative work with staff to devise the specific learning outcomes. Not only that, they were supported in visualising what good achievement in the outcomes 'looks like', which staff felt had the potential to promote a 


\section{Articles}

deeper approach to learning. Performance in the module was not significantly different from that of previous years, with the vast majority $(94 \%)$ passing the module first time. The main themes arising from the data are discussed below:

\section{Pace and structure of the module}

A number of the questions dealt with 'organisational' issues, such as the pace of delivery and the distribution of content within the module. The authors also considered questions about feedback to fall within this theme, as opportunities for reflection and feedback were specifically built into the new structure of the module and the design was intended to allow adequate time for students to use the feedback from the formative assessments to prepare for the summative elements. $69 \%$ of respondents agreed or strongly agreed that the module was well-paced, allowing adequate time to prepare for the summative assessment. Of the remaining respondents, it is possible that their difficulties with the pace and structure stemmed from a difference in understanding of the overall aim of the collected activities. One respondent felt that "having lots of different [elements] made it quite hard to keep on top of." This is interesting when compared with the response from a student content with the pace and structure: "every week we collaborated and expanded our knowledge in the courseworks..." and with that of another who reported feeling that the "group work for the cardiovascular risk assessment was focused on... doing the risk assessment with a patient." It was the aim of the teaching team to use the cardiovascular risk assessment as a scaffold round which to build the teaching and learning activities required to deliver effectively on the learning outcomes. Perhaps not all students understood this completely and so this is one area for future development.

Figure 1 shows the results obtained for the statement 'I felt that I received timely and constructive feedback from the formative assessment which allowed me to improve for the summative.' $82 \%$ of respondents agreed or strongly agreed. While the response rate was low, the results are supported by the comments seen in the Student Experience Questionnaire: the comments regarding feedback were frequent and positive, which was very encouraging, given how low feedback scores (measured using instruments such as the NSS) are across the sector. For those students who felt the feedback was inadequate, it is again possible that this is down to a lack of understanding of (or, indeed, to discomfort with) the approach. One respondent commented: "We had a risk assessment which was confusing, pupils were unaware of what was going on some weeks and were unsure what was actually asked of us for this assessment." The reality was that, while the module-level outcomes were pre-defined, the 'micro-level' outcomes for achievement in the cardiovascular risk assessment were to be negotiated by the students themselves, and consequently were not available in their final form until quite late in the module. This was a deliberate approach, designed to promote deeper engagement with assessment criteria, but, as it is quite different from anything else the students will have encountered previously, it may therefore possibly provoke a degree of anxiety. 


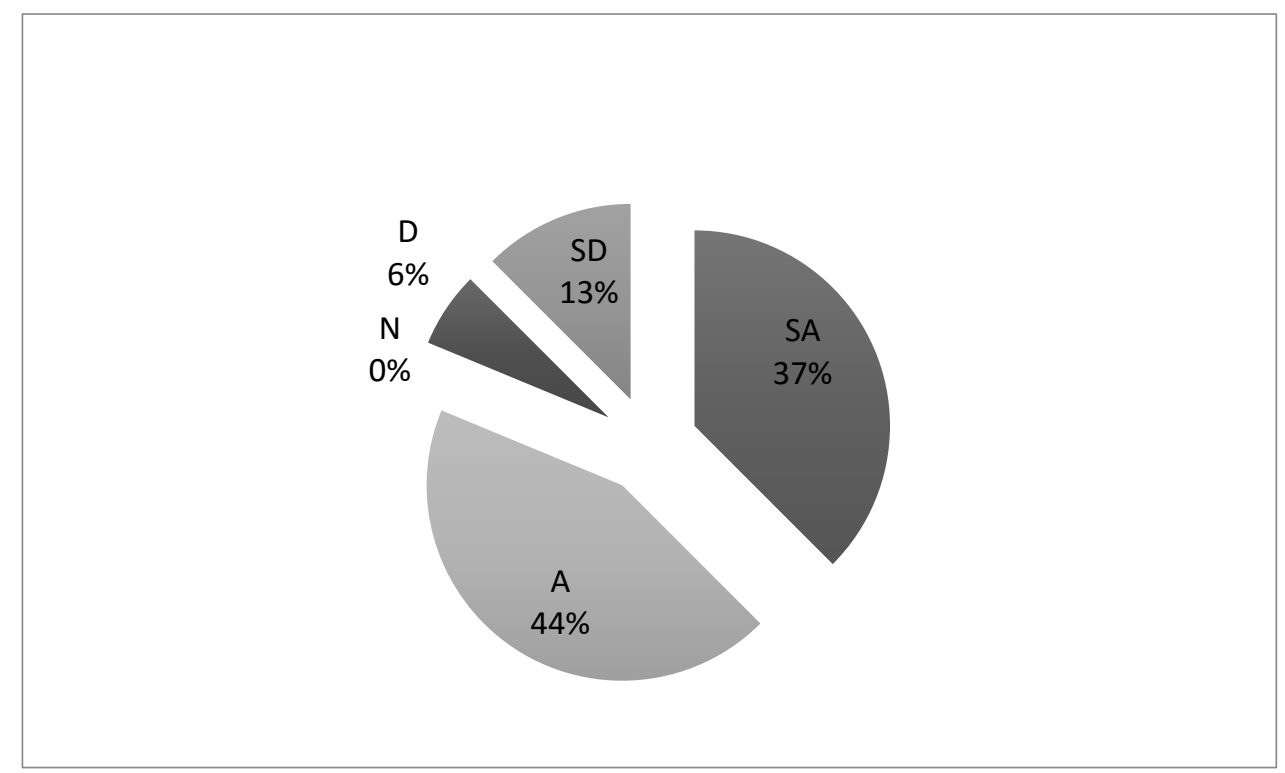

Figure 1. 'I received timely and constructive feedback on my work' (SA=strongly agree; $\mathrm{A}=$ agree; $\mathrm{n}=$ neutral; $\mathrm{D}=$ disagree; $\mathrm{SD}=$ strongly disagree)

\section{Use of simulation}

Three questions addressed the use of simulation as a teaching and learning activity. Students were asked if they felt that simulation was a helpful method of learning, if they felt that simulation allowed them to contextualise lecture content and whether they would like to see greater use of this approach to learning. With the exception of one respondent, all students responded positively to these questions (either agreeing or strongly agreeing). This reflects the responses seen in the Student Experience Questionnaire. With regard to expanding the use of simulation, students came forward with a number of suggestions for how this might be done. These included the addition of related consultations, such as smoking cessation, as well as of more complex cases.

Simulation allowed the students to practise within the safe confines of the course. Specifically, they remarked on the value of the preparatory sessions that allowed them to identify and plan to deal with some of the potentially difficult aspects of the risk assessment. The reality is that risk assessment is judgmental, with patients' having to reveal very personal information, such as waist circumference, weight and diet. Simulation provided the opportunity to test different ways of communicating with the patient, allowing 'acting out' of examples of poor behaviours. These vignettes acted as focal points for discussion which supported the students in developing more positive approaches. Similarly, defining the indicators of good, acceptable and poor behaviour was "a great approach to learning as it made [students] realise how pharmacists should speak to their patients," as well as "putting into perspective ways in which as a pharmacist we can maximise patient care."

Students were asked which mode of delivery best suited their own learning style (Figure 2). Interestingly, simulation scored most highly at $38 \%$, which suggests that it may be useful route for promoting student engagement, in addition to the established benefits in terms of achievement of learning outcomes described in the introduction. 


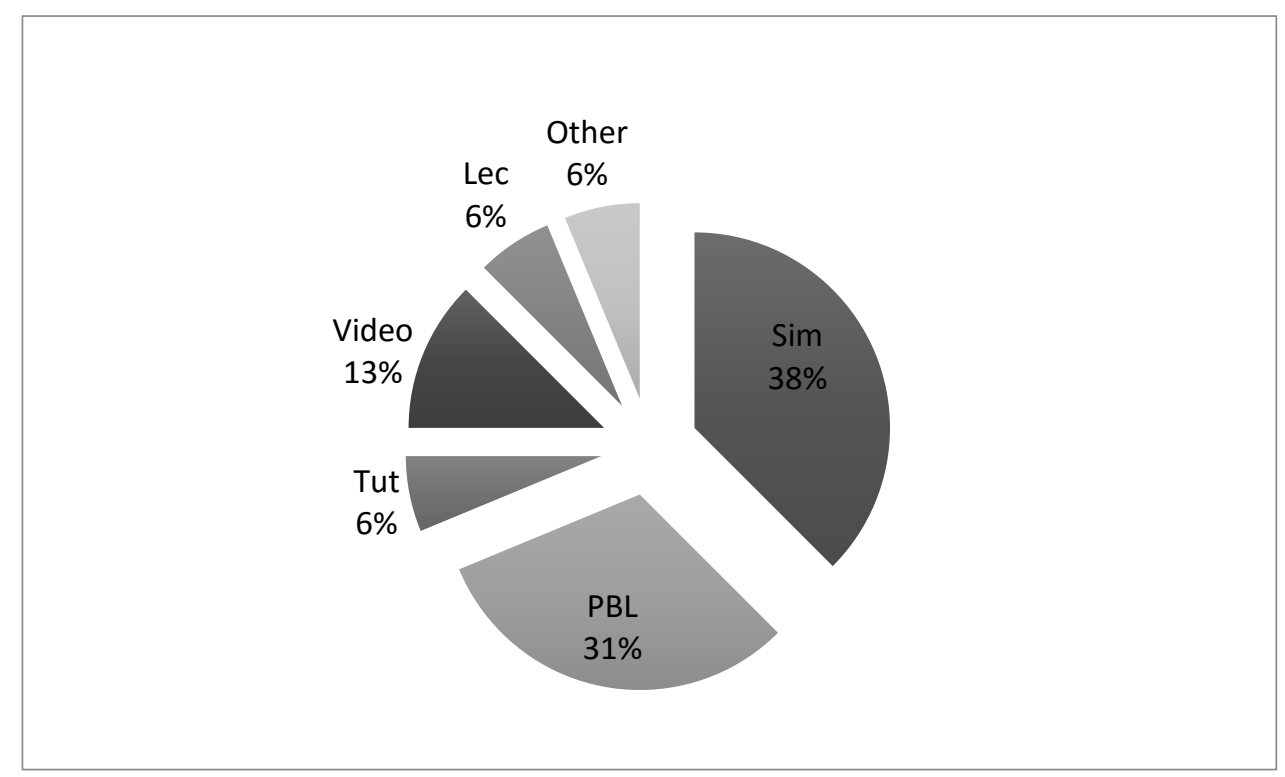

Figure 2. What is your preferred type of learning activity? ( $\mathrm{Sim}=$ simulation; $\mathrm{PBL}=$ problembased learning; Tut=tutorial; Video=video case study; Lec=lecture)

\section{Staff behaviours}

The delivery style of this module depends very much on staff acting as facilitators of student learning. Student perception of the effectiveness of 'staff as facilitators' was explored through a number of questions, including 'I felt comfortable in sharing my thoughts, experiences and opinions during lectures and coursework sessions.' $69 \%$ of respondents agreed or strongly agreed with this statement (Figure 3). This reflects comments from the Student Experience Questionnaire and seems high: anecdotally, staff often report that students seem to feel very uncomfortable with sharing ideas within a group, especially given the large MPharm cohort (even small group teaching is likely to involved thirty-five students or more). It is possible that this comfort stemmed from the staff behaviour towards the students. Many comments related directly to the demonstrable interest by the teaching staff in their students and to their efforts to seek engagement:

"...they seemed to care very much that we learned well and even though the module was set up slightly differently this year they made sure we understood what was happening at every point."

"...[lecturers] have a great way of getting the best out of their students. Coursework sessions were very relaxed, interactive, with the lecturers going round to each bench and addressing any concerns or questions we had."

It also appeared that the students were aware of the difficulties relating to the delivery of a new module and found that the engagement and commitment of staff served to heighten their own. The various ways in which teaching staff made themselves available for students, to support them in directing their own learning, was frequently noted. Merriam (2001) describes states such as this as 'an adult classroom' within which exists 'a spirit of mutuality between teachers and students as joint inquirers.' 


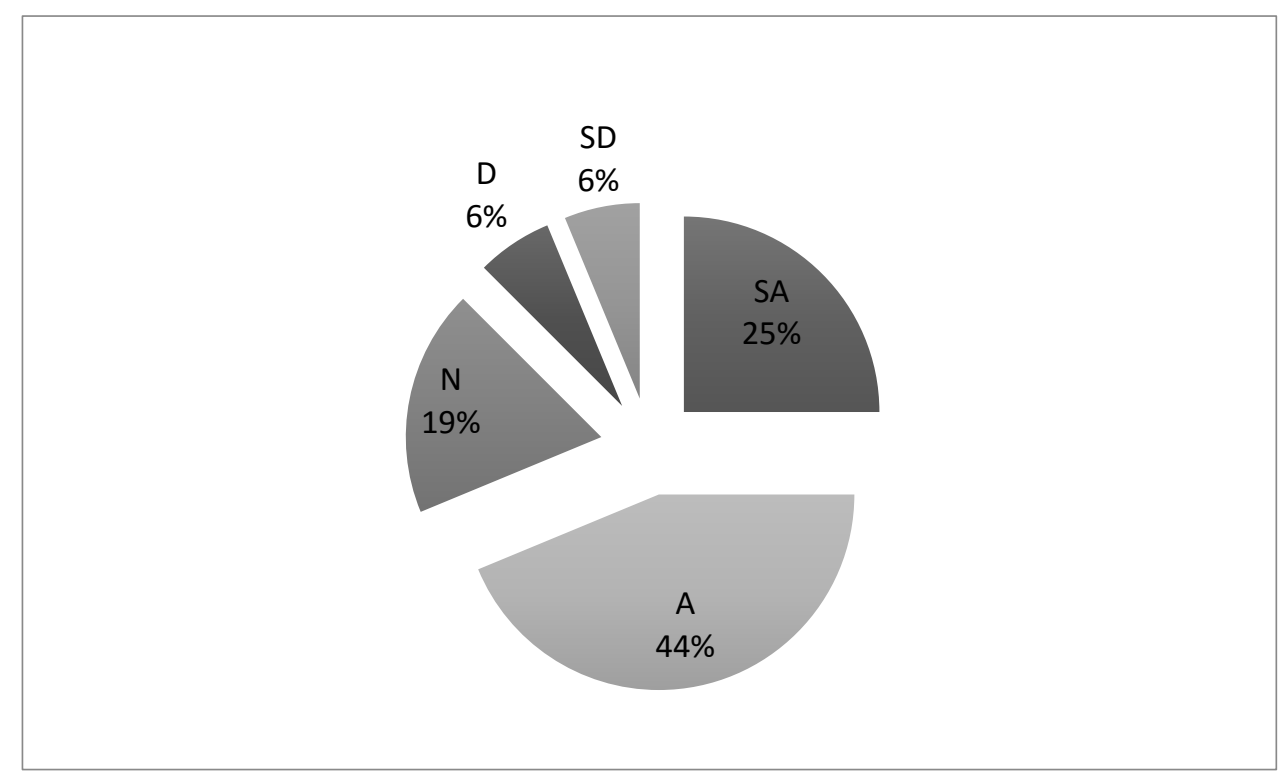

Figure 3. 'I felt comfortable sharing my thoughts, experiences and opinions' (SA=strongly agree; $\mathrm{A}=$ agree; $\mathrm{N}=$ neutral; $\mathrm{D}=$ disagree; $\mathrm{SD}=$ strongly disagree

\section{Enhancement of future delivery}

One of the free-text sections invited student suggestions for improvement. Some of these suggestions have already been discussed (such as the introduction of additional simulations). One frequently-recurring theme (also mirrored in the Student Experience Questionnaire) was the lack of an obvious relationship between these activities and those which had been delivered in Semester 1 (primarily centred upon disorders of the central nervous system and mental health). One option may be to include aspects of these conditions in the more complex scenarios suggested earlier.

\section{Conclusions}

This has been an extremely interesting and rewarding piece of work, which has had impact on a large number of students (and staff). Our results suggest that students feel challenged by such an approach, but feel sufficiently supported to meet that challenge. The students who developed the teaching and learning materials also appeared to gain additional benefits: for example, the two videos created by final-year project students (LH, LK, SM) were intended to be examples respectively of excellent practice and of poor practice, to allow students to explore this in more detail. However, on reflection, the students decided that they hadn't achieved quite the distinction they'd hoped to achieve: there were elements of good practice in the 'poor' video and vice versa. Recognition of this may well have arisen as a result of their increased knowledge of cardiovascular risk.

It is estimated that this student-led activity has had direct impact on over 150 students in this academic session and will continue to do so, as the activities will run again in the next academic session. Many of the students also expressed a belief that the activities were highly relevant to their future careers and commented on the value of the approach in helping them to understand the links between practice and the underpinning science. Finally, some of the students involved in this engagement are in the process of applying for professional recognition with the Higher Education Academy (at Associate Fellow level) and 


\section{Articles}

are considering pharmacy teaching as another career option - this was an entirely unanticipated effect and shows the value of meaningful student engagement beyond the enhancement of the taught provision.

Reflections on the student partnership

This project is an example of how engagement with a small number of students can have an impact on many. It also provides an example of how meaningful engagement and mitigation of some of the associated risks can be simultaneously achieved. The staff involved have found the process incredibly rewarding as illustrated by the following quote:

"It has been a privilege and pleasure to work with the group of pharmacy students involved in delivering the enhancement projects. Their enthusiasm and engagement is exemplary and demonstrates their commitment to the benefits that result from students being co-creators of teaching, learning and assessment resources. Key to the success of the various projects that this wonderful group of students have been involved in is their openness to new ideas and their readiness to embrace a novel role in the development of educational strategies and materials. They have also been prepared to work in collaborative partnerships with staff requiring mutual respect and trust and recognition of the importance of establishing shared values and goals."

The students involved expressed similar opinions, but also talked about how their input had additional benefits in terms of helping them understand more deeply the principles of curriculum design and the concept of barriers and facilitators with respect to change:

"...working in a partnership with academic staff members increased my overall understanding of how our curriculum was designed. So often, as a student, I have felt that I had little to no control over the courses I undertook. This was an excellent way to see how much our input has modified the course along the way and how much effort goes into the planning and execution of our learning activities."

A further advantage of this model is the small-scale nature of the individual projects - the approach resembles that of quality improvement in healthcare: change can be explored without risk to the curriculum and successful initiatives can be scaled-up to increase the impact.

\section{Reference list}

Bryant, L.J.M., Coster, G., Gamble, G.D., McCormick, R.N. (2009) 'General practitioners' and pharmacists' perception of the role of community pharmacists in delivery of clinical services.' Research in Social and Administrative Pharmacy 5, 347-362.

Fanning, R.M., Gaba, D.M. (2007) 'The role of debriefing in simulation-based learning.' Simulation in Healthcare 2(2), 115-125.

General Pharmaceutical Council (2010) 'Standards for the initial education and training of pharmacists.' Available at: http://www.pharmacyregulation.org/education/educationstandards (Accessed: 20 September 2014).

Horgan, J.M., Blenkinsopp, A., McManus, R.J. (2010) 'Evaluation of a cardiovascular disease opportunistic risk assessment pilot ('Heart MOT' service) in community pharmacies.' Journal of Public Health 32,110-116. 


\section{Articles}

McClinchy, J., Dickinson. A., Barron, D., Thomas, H. (2013) 'Practitioner and patient experiences of giving and receiving healthy eating advice.' British Journal of Community Nursing 18(10), 498-504.

National Health Service Scotland (2011) 'A route map to the 2020 Vision for Health and Social Care.' Available at: http://www.scotland.gov.uk/Topics/Health/Policy/QualityStrategy/routemap2020vision (Accessed: 20 September 2014).

National Quality Board (2013) 'Human factors in healthcare. A concordat from the National Quality Board.' Available at: http://www.england.nhs.uk/wp-content/uploads/2013/11/nqbhum-fact-concord.pdf (Accessed: 20 September 2014).

Regan, K., Harney, L., Goodhand, K., Strath, A., Vosper, H. (2014) 'Pharmacy simulation: A Scottish, student-led perspective with implications for the UK and beyond.' Pharmacy 2, 5064.

Seybert, A. (2011) 'Patient simulation in pharmacy education.' American Journal of Pharmacy Education 75(9), Article 187.

Smith, A., Darracott, R. (2011) Review of pharmacist undergraduate education and preregistration training and proposals for reform. Report to the Medical Education England Board.

Vosper, H., Brown, A., Mackenzie-Fraser, M., Goodhand, K., Joseph, S., Diack, L. (2013) 'Simulation as a tool for supporting teaching, learning and assessment in an undergraduate pharmacy programme.' Compendium of Effective Practice in Higher Education: Volume 2. The Higher Education Academy, York, UK. Available at: http://www.heacademy.ac.uk/assets/documents/retention/Compendium 2 rc ja Final.pdf (Accessed: 20 July 2014). 